\title{
ENSAIO REFLEXIVO SOBRE A CRISE DO CONHECIMENTO CIENTÍFICO NA PERSPECTIVA DE EDGAR MORIN
}

\author{
Lucas Prado Osco, Rodrigo Coladello Oliveira, Munir Jorge Felício, Marcos Norberto Boin \\ Universidade do Oeste Paulista - UNOESTE. Mestrado em Meio Ambiente e Desenvolvimento Regional, Presidente \\ Prudente-SP. E-mail: pradoosco@gmail.com
}

\section{RESUMO}

Este texto tem por principal objetivo abordar a crise do conhecimento científico sob o viés do antropólogo e filósofo Edgar Morin, fundamentando-se especificamente em sua obra "Ciência com consciência" (2005), onde o autor debate a respeito das condições e oposições responsáveis pelo enfraquecimento da ciência. Para tanto, o presente artigo discorre sobre os fatores cruciais que contribuíram para a presente situação do conhecimento científico. Posteriormente, abordamse outros autores com o intuito de fundamentar a discussão levantada por Morin. Assim, os elementos debatidos no presente trabalho procuram esclarecer as deficiências encontradas na ciência contemporânea, enfatizando em especial o impedimento imposto pelo sistema econômico capitalista sobre o pesquisador. Denomina-se, deste modo, a crise do saber, onde a ciência, ao encontrar-se fragmentada, apresenta-se submissa às diretrizes fixadas pelo capital.

Palavras-chave: Capitalismo; Ciência; Fragmentação.

\section{REFLECTIVE ESSAY ON THE CRISIS OF THE SCIENTIFIC KNOWLEDGE IN THE PERSPECTIVE OF EDGAR MORIN}

\begin{abstract}
This text is primarily engaged in addressing the crisis of the scientific knowledge under the anthropologist and philosopher Edgar Morin vision, building upon specifically in his "Science with conscience" (2005), where the author discus about the conditions and oppositions responsible for the weakening of science. To this end, this paper discusses the key factors that contributed to the present state of the scientific knowledge. Subsequently, other authors are approached in order to substantiate the argument raised by Morin. Thus, the elements discussed in this paper seek to clarify the deficiencies found in contemporary science, emphasizing in particular the impediment imposed by the capitalist economic system on the researcher. It is named has the crisis of knowledge, where science, to find themselves fragmented, presents submissive to the guidelines established by the capital.
\end{abstract}

Keywords: Capitalism. Science. Fragmentation. 


\section{INTRODUÇÃO}

Ao discutir-se a ciência, deparamo-nos com imposições e limitações que caminham paralelamente ao desenvolvimento do saber científico. Estas condições, majoritariamente, são responsáveis por reger aquilo que deve (ou não) ser considerado como a verdade. Esta, então denominada verdade, muitas vezes não compreende ou mesmo reflete a realidade que tanto assiduamente procura explicar. É preciso, preliminarmente, salientar os principais fatores que culminaram para o advento da crise do conhecimento. Este texto abordará, em especial, a obra de Edgar Morin, "Ciência com consciência", alimentado por trabalhos científicos, com o intuito de estabelecer elos existenciais entre os pontos de vista defendidos por seus autores.

Inicialmente, há que atestar-se uma série de considerações estabelecidas pelo autor mencionado, demonstrando, desde o princípio, que "Essa ciência libertadora traz, ao mesmo tempo, possibilidades terríveis de subjugação." (MORIN, E. p. 16, 2005). Torna-se, deste modo, evidente que o progresso científico - embora provedor do avanço tecnológico - encontra-se submisso às diretrizes impostas pelo sistema a que está inserido. Entretanto, devemo-nos recordar, incessantemente, de que a crise do pensamento científico atinge patamares divergentes, e, concomitantemente inter-relacionados, conforme será debatido adiante. Esta crise, portanto, parte do princípio onde existe a exploração do conhecimento, benigno ou não, e a incapacidade intrínseca do entrave reflexivo do próprio saber.

Outra questão apontada pelo autor apoia-se no distanciamento das ciências naturais e humanas, conforme se apresenta evidente nos seguintes dizeres: "Constituiu-se grande desligamento das ciências da natureza daquilo a que se chama prematuramente de ciência do homem." (MORIN, E. p. 16, 2005). Ora, essa declaração proporciona o entendimento e afirmação de que, como implicação do desmembramento entre as ciências, ocorrida com a verticalização e especialização do conhecimento, o "[...] saber científico tem como conseqüência a tendência para o anonimato." (MORIN, E. p. 17, 2005), enquanto que se torna objeto e instrumento de subvenção para os setores manipuladores e detentores do poder, promovidos e enriquecidos pelo desenvolvimento econômico vigente sobre a sociedade atual. Ou seja, encontrando-se sujeitas aos interesses estatais e capitalistas.

\section{METODOLOGIA}

O presente artigo embasou-se, conforme relatado, na obra de Edgar Morin "Ciência com consciência" (2005), ressaltando pontos específicos relacionados à crise contemporânea do conhecimento científico, oferecendo, como finalidade, a construção de um debate reflexivo a 
respeito do tema abordado. Este debate, consequentemente, fundamenta-se nas demais concepções elencadas por autores como Arrighi (1999), Felício (2003), Huberman (1999), dentre outros. Por último, o texto procura estabelecer critérios reflexivos acerca do processo científico, salientando as consequências impostas pelo sistema econômico capitalista e pela incapacidade de autorreflexão do próprio conhecimento.

\section{RESULTADOS E DISCUSSÃO}

A partir deste ponto, cabe ressaltar os principais aspectos da edificação do capital, de modo a elucidar o papel dos interesses econômicos na sociedade, e, portanto no cunho científico. Assim, com o intuito de compreender os acontecimentos que os levaram a estas condições, é oportuno regressar-nos às situações e eventos que antecederam o capitalismo atual. Huberman (1979) discute a questão do capital e dos acontecimentos que o trouxe até a sua posição no início do século XX. Em sua obra "História da Riqueza do Homem", o autor revela que o sustento do capital não está contido somente na moeda em si, mas no valor atribuído a força de trabalho humano. Para tanto, o autor apresenta-nos uma série de constatações, iniciando com observações referentes ao sistema feudal, determinado pelas classes sociais compostas por sacerdotes, guerreiros e trabalhadores. Posteriormente, a ríspida mudança deste modo de vida para o atual apenas evidencia a série de fatores históricos ulteriores.

A acumulação capitalista, conforme Huberman (1979), ocorre no momento em que o dinheiro é empregado a um empreendimento, tornando-se possível a obtenção do lucro e resultando no capital. O autor demonstra que os capitalistas detêm os meios de produção, privando o trabalhador destes meios, o condenando a vender sua força de trabalho em troca da sobrevivência. Entretanto, para que este capital se acumule, é imprescindível à existência da oferta de trabalho, de modo a satisfazer o próprio sistema. Até então, o ser humano não trabalhava por obrigatoriedade, pois detinha terras e os serviços prestados consistiam-se meramente na troca de mercadorias, não visando a sua lucratividade.

Deste modo, Huberman (1979) demonstra que, com a iniciação do processo industrial, os camponeses, ao perderem suas terras, tornaram-se trabalhadores assalariados. Ao eclodir este sistema, o domínio da moeda concretizou uma série de modificações aos valores atribuídos ao trabalho, criando a necessidade de economizar e investir. Ainda dentro deste sistema, ressaltamse os processos e mudanças engendrados na própria religião, pois:

[...] numa sociedade em que o objetivo do trabalho era apenas conseguir um sustendo adequado para si e para a família, a Igreja podia denunciar os aproveitadores. Mas numa sociedade em que o principal objetivo do trabalho 
era o lucro, então a Igreja tinha de adotar uma linguagem diferente. (HUBERMAN, L. p. 179, 1979).

Posteriormente, a ascensão da maquina a vapor permitiu a expansão do mercado em razão do aumento da demanda de novas mercadorias e da agilidade no processo de entrega ao consumidor. Ressalta-se, no mesmo período, o aumento demográfico da população, devido à evolução da medicina e ao então progresso na produção de alimentos. 0 transporte também acompanhou a revolução industrial, possibilitando o crescimento do mercado interno e mundial. Esta produção, entretanto, resultou no agravamento da situação do trabalhador, pois este se encontrava submetido a longas jornadas de trabalho exaustivas e mau pagas, o que imponha ao mesmo a dependência e subordinação ao sistema, convencendo-o que esta jornada duradoura seria uma possível conveniência para o seu desenvolvimento profissional (HUBERMAN, 1979).

Em outra abordagem, Arrighi (2009), ao publicar "O Longo Século XX", demonstra que o desenvolvimento do capitalismo moderno atravessa um período decisivo, provocando modificações no processo de acumulação do capital. Para tanto, o autor organiza as fases que precederam o capitalismo atual em ciclos. Estes ciclos, por sua vez, são representados por quatro etapas fundamentais, onde a primeira consiste no ciclo genovês (século XV - XVII), a segunda no ciclo holandês (fim do século XVIII), a terceira no ciclo britânico (século XIX) e a quarta no ciclo estadunidense (século $X X$ ), sendo que cada etapa expressa à tendência geral de expansão do mercado capitalista. O regaste redigido pelo autor evidência uma série de constatações, revelando, entre as mesmas, que:

[...] a concorrência interestatal foi um componente crucial de toda e qualquer fase de expansão financeira, bem como um fator de vulto na formação de blocos de organizações governamentais e empresariais que conduziram a economia capitalista mundial por suas sucessivas fases de expansão material. (ARRIGHI, G. p. 12-13, 2009).

Por conseguinte, Arrighi (2009) dá continuidade a sua proposta ideológica, onde ressalva que a economia capitalista mundial caracterizou-se como um sistema em que as redes de acumulação encontravam-se inseridas nas redes de poder instituídas, estando, consequentemente, relacionadas às mesmas. Tamanha modificação do capital transcorreu-se nesses ciclos, incidindo-se em fases de expansão - material e financeira - oriundas de operações conduzidas por interesses estatais e empresariais, tendo assim, sua capacidade sujeita a estes agentes, sendo que a expansão se dava fora dos limites e pretensões instituídos pelos próprios autores e fomentadores da expansão anterior. 
Já em alusão à procedência do capital, Arrighi (2009) prenuncia que este se originou a partir de um sistema social histórico, sendo este originado em razão da potencialização da competição intercapitalista somado a luta pela supremacia e poder do sistema emanada no interior (bem como ao entorno) das denominadas cidades-estados. Tamanho controle dos Estados, conduzidos pelos interesses do capital, proporcionou o arrebatamento dessas cidadesestados para o interesse monetário - tal qual se tornou a feição primordial da ampliação financeira do ciclo genovês - devido ao fato de que os grupos capitalistas não mais obtinham meios de investir no mercado através do ganho, e, a partir de então, passaram a investir na tomada de mercados competidores. Este modelo consentiu ao capital apropriar-se, internamente, dos bens e receita do Estado onde o mesmo agia.

Deste modo encontra-se exposta a breve edificação do sistema capitalista mundial. É este sistema capitalista, portanto, que inúmeras vezes, em sua ânsia por saquear os recursos necessários ao seu desenvolvimento e crescimento, determina as diretrizes mandatórias para reger uma sociedade tal qual o mesmo julga condizente, utilizando, dentre os mais diversos instrumentos manipulativos, a própria ciência. Para tanto, o conhecimento científico, estando à mercê do capital, nada mais incide como uma artimanha de seu interesse, pois:

[...] os poderes criados pela atividade científica escapam totalmente aos próprios cientistas. Esse poder, em migalhas no nível da investigação, encontra-se reconcentrado no nível dos poderes econômicos e políticos. De certo modo, os cientistas produzem um poder sobre o qual não têm poder [...] (MORIN, E. p. 18, 2005).

Obviamente que esse poder científico, quando subjugado ao sistema capitalista, admite e adquire caráter maleável, de modo a alimentar os interesses econômicos do capital, em apoio em consecutivas situações - do próprio Estado. Isso, conforme o autor aludido, consiste-se em uma deficiência reflexiva do saber científico, onde a produção tecnológica suplanta a verdade, e a questão ideológica aparenta-se de modo infundado, dando espaço para que a técnica, produzida pela ciência, torne-se o instrumento das instâncias em poder .

Separa-se, portanto, o que diz respeito aos processos científico e técnico. 0 desenvolvimento da ciência experimental, por si, permitiu ao capital esta capacidade manipuladora dos dados e informações, e, na narrativa de Morin (2005), essa “[...] enorme massa do saber quantificável e tecnicamente utilizável não passa de veneno se for privado da força libertadora da reflexão." (E. MORIN, p. 21, 2005). Entretanto, a afirmação supracitada demonstra um caráter "fetichizado" ao manifestar que essa ciência não reflexiva consiste-se, em sua plenitude, somente como um instrumento nocivo, que "[...] se difunde por intermédio do 
pensamento fetichizado que só poderá ser desfeito à medida que os pesquisadores forem construindo uma cientificidade priorizando nela o desenvolvimento do mais alto nível de consciência [...]". (FELíCIO, M. J. p. 196, 2013).

No entanto, é preciso que se compreendam as características do pensamento fetichizado conforme demonstrado por Felício (2013), onde a aparência fenomênica do objeto nada mais é que um reflexo consequente de um paradigma enraizado. Essa aparência, por sua vez, quando analisada sem o aparato reflexivo necessário, é interpretada de modo errôneo e superficial, ocultando a essência ou verdade por detrás de seu semblante. É notável, portanto, que as imposições e submissões concebidas pelo sistema capitalista:

[...] são intermediadas pela comoditização do fetiche cada vez mais sedutor, que, do interior da mercadoria, impede o ser humano de se reconhecer como produto de sua própria atividade histórica e coletiva. Eis, portanto, a gênese do pensamento fetichizado. Ao emergir e evoluir vai "endeusando" o capitalismo que se sustenta por causa da sua enorme produtividade a qual, muitas vezes, é utilizada como anteparo impedindo o reconhecimento e a identificação de suas contradições geradas em seu entorno [...] (FELÍCIO, M. J. p. 201, 2013).

Deste modo, cabe ressaltar que a crise científica aprofunda-se em outras questões, e os fatores limitantes, até então aparentemente instituídos exclusivamente por agentes externos à pesquisa (advindos da desmistificada "supremidade" do capital), consistem-se, unicamente, como apenas uma fração da crise do saber. Neste sentido, é imprescindível demonstrar que o próprio conhecimento não possui os mecanismos necessários para concretizar-se uma autoanálise, admitindo que "[...] ninguém está mais desarmado do que o cientista para pensar sua ciência." (MORIN, E. p. 21, 2005). É compreensível que esta inabilidade do saber acarrete em implicações e consequências regressivas para o desenvolvimento da sociedade, enquanto que, simultaneamente, oferece a mesma uma visão de aparência fenomênica, onde este avanço tecnológico é distinguido como a essência, levando-nos a admitir, equivocadamente, em uma crise infundada do saber científico.

Assim, na medida em que a ciência e a sociedade percorram por caminhos relacionados entre si, é preciso que se tenha em mente a necessidade da integração de ambos os elementos. A questão discutida por Morin (2005), apontando para a então fragmentação do saber, nada mais evidência que o enfraquecimento do pensar científico. Esta preocupação, referente à perda substancial dos elos conectivos entre as diversas disciplinas, engendrou a carência de organizar-se um modelo teórico-metodológico onde seria possível resgatar a junção de um conhecimento único. O autor repete, continuamente, os dizeres do físico, matemático, filósofo e teólogo francês 
Blaise Pascal, ao pessoalmente afirmar que: "Só posso compreender um todo se conheço, especificamente, as partes, mas só posso compreender as partes se conhecer o todo." (MORIN, E. p. 181-182, 2005).

Ora, a partir do momento que se consegue assumir a existência dessa desvinculação científica interna, permitimo-nos refletir a respeito da fragmentação e particularização do saber. Até meados do século XX o cientista poderia dominar diversas áreas do conhecimento, no entanto, com o aprofundamento e verticalização dos estudos, o separatismo entre as ciências permitiu a extinção de um domínio integrador. Este processo intrínseco do conhecimento agravou as relações substanciais entre as ciências. Para tanto, é imprescindível compreender que:

[...] a ciência está no âmago da sociedade e, embora bastante distinta dessa sociedade, é inseparável dela, isso significa que todas as ciências, incluindo as físicas e biológicas, são sociais. Mas não devemos esquecer que tudo aquilo que é antropossocial tem uma origem, um enraizamento e um componente biofísico. E é aqui que se encontra a dupla tarefa cega a ciência natural não tem nenhum meio para concebesse como realidade social; a ciência antropossocial não tem nenhum meio para conceber-se no seu enraizamento biofísico; a ciência não tem os meios para conceber seu papel social e sua natureza própria na sociedade. (MORIN, E. p. 20, 2005).

Subentende-se, desta maneira, que a aproximação entre ambas às ciências, humanas e naturais, consistira como um sinônimo da então necessidade de unificação do conhecimento. 0 exercício reflexivo, entretanto, não deve privar a conexão empírica, pois esta, muitas vezes, condiz-se com um dos pilares do alicerce que sustenta toda uma base teórica. É notável que o "encastelamento" do cientista como único e singular ser pensante trouxesse consequências - tais quais levantadas previamente no texto - para o desenvolvimento da própria ciência, de modo que uma passasse a negligenciar à outra. Cabe, portanto, brevemente mencionar a respeito de questões relacionadas aos conceitos de interdisciplinaridade, ou até mesmo transdisciplinaridade, constantemente debatidos no meio acadêmico, individualizando-se pelo desafio do seu dificultado exercício.

As propostas pedagógicas, ao empregarem sentido de multi, inter ou de transdisciplinaridade, sugerem a reconquista do conhecimento integrador de múltiplas disciplinas. Entretanto, esta ânsia de fortificação do saber científico muitas vezes caminha contrariamente ao interesse econômico do capital, o que contribui para estorvar sua funcionalidade. Não obstante, embora o sistema capitalista tenha poder, este é hipertrofiado em razão do pensamento fetichizado que contribui para a sua potencialização. Em um dizer simplista e análogo: "a sombra da criatura é maior do que a criatura propriamente dita". Ainda sim, a ciência encontra-se, 
parcialmente, vassala deste poder, pois o pesquisador por si representa a possibilidade de tornarse uma das armas do capital - quando corrompido por sua vontade - ao desenvolver uma ciência auxiliadora do setor explorador.

\section{CONCLUSÃO}

Para tanto, é plausível concluir que não podemo-nos permitir, ou ser induzidos a crer, que a aparência fenomênica concretiza-se somente como o reflexo absoluto da realidade, pois esta é, igualitariamente, reveladora do conteúdo contido em sua essencialidade. Por outro lado, deve-se acrescentar que, além da busca pela retomada do conhecimento integrador, o pesquisador carece de atentar-se para as implicações impostas pelo próprio sistema econômico atuante, pois este sistema lhe oferecerá e imporá barreiras diante de sua pesquisa. Não obstante, o cientista também se encontra sujeito à corrupção, sendo responsável por desenvolver uma ciência não apenas desvirtuada, mas sujeita as indigências promovidas pelo capital. Em razão destes dizeres, reforça-se o emprego reflexivo do pesquisador, para que o mesmo compreenda e interprete, à sua maneira, a realidade que o cerca, de modo a se perguntar para que, quem e onde sua ciência o levará.

\section{REFERÊNCIAS}

ARRIGHI, Giovanni. O Longo Século XX: dinheiro, poder e as origens de nosso tempo. 7ạ impressão. Rio de Janeiro: Contraponto, 2009.

FELÍCIO, Munir Jorge. Apontamentos de Epistemologia Ambiental. Geoambiental On-line. Revista Eletrônica do Curso de Geografia - Campus Jataí - Goiás, 2013.

HUBERMAN, Leo. História da Riqueza do Homem. 15 Edição. RJ: Zahar Ed., 1979.

MORIN, Edgar. Ciência com Consciência. 8" ed. - Rio de Janeiro: Bertrand Brasil, 2005. 